\title{
Effect of Septal Deviation, Concha Bullosa and Haller's Cell on Maxillary Sinus's Inferior Pneumatization; a Retrospective Study
}

\author{
Gökhan Göçmen*, Mehmet Oğuz Borahan, Sertac Aktop, Asım Dumlu, Filiz Namdar Pekiner \\ and Kamil Göker
}

Marmara University, Faculty of Dentistry, Department of Oral \& Maxillofacial Surgery, Istanbul, Turkey

\begin{abstract}
Purpose: Maxillary sinus's inferior pneumatization is a physiological process, which increase with time and accelerates following extraction. The aim of this study was to determine the prevalence of nasal septal deviation (NSD), concha bullosa (CB), and Haller's cells ( $\mathrm{HC}$ ) and to examine the correlation of maxillary sinus inferior pneumatization (MSIP) with these anatomical variations. Material and Methods: $300(150 \mathrm{~m}, 150 \mathrm{f}) \mathrm{CBCT}$ scans taken at the Marmara University School of Dentistry from 2011 to 2014 were retrospectively reviewed for the presence of CB, NSD, HC and MSIP. The correlation between pneumatization to the anatomic variants was then compared. Data were analyzed with a Chi-square test. Results: Of the 300 CBCT scans, $44.3 \%$ have CB, 37.3\% NSD, 19.3\% HC and $27.7 \%$ MSIP. There was no statistical significancewhen comparing the relationship of patients with $\mathrm{CB}$, NSD, HC and pneumatization. Conclusion: NSD, CB and HC do not have a definite role on sinus's inferior pneumatization. Further studies should be conducted including potential factors related pneumatization with more sample size for further correlation with NSD, CB,HC.
\end{abstract}

Keyword: Concha bullosa, Haller's cell, nasal septal deviation, maxillary sinus pneumatization.

\section{INTRODUCTION}

Themaxillary sinus enlarges variably and greatly until it reaches the adult size by the eruption of permanent teeth. Although its growth slows down with the decline of the facial growth during puberty but continues throughout life. This physiological process is called maxillary sinus pneumatization [1]. Inferior pneumatization, extension of maxillary sinus into the alveolar process, is a common encountered situation which is clinically important considering tooth extraction or insertion of dental implants in to the region

Sinus pneumatization might be affected from craniofacial configuration, density of the bone, age, sinus air pressure, and sinus surgery. It is generally accepted that pneumatization increases with fume and extraction accelerates this process [2, 4].

Some studies describe resumption of maxillary sinus's inferior pneumatization following tooth extraction increase over time [5]. Maxillary sinus extends further by osteoclast activity in the Schneiderian membrane, causing pneumatization of the sinus by resorbing bone [5]. However, other studies have produced contradictory findings, which present alveolar extension of maxillary sinus between teeth with displacement of their roots [3].

*Address correspondence to this author at the Marmara University Oral and Maxillofacial Surgery Department, Büyük Çiftlik Sk. No: 634365 Nisantasi, Turkey; Tel: 902122319120; Fax: 902122465247;

E-mails: gocmengokhan@ hotmail.com, gokhangocmen@gmail.com
Several authors have assessed the relationship between sinonasal anatomic variants and the incidence of sinus pathology. The incidence of Haller's cells (HC) has been reported to vary from $2-45 \%$ and some reports have found statistically significant relationship between maxillary sinusitis and Haller Cells. Concha Bullosa (CB) is a common anatomic variant and there is a strong association between the presence of $\mathrm{CB}$ and contralateral NSD [6]. NSD, the presence of $\mathrm{CB}$, NSD or $\mathrm{HC}$ can be listed as common anatomical variations leading sinonasal obstructions [7]. It is widely believed that osteomeatal obstructions may impede ventilation and mucociliary clearance from the sinuses [1]. Less is understood about the role of NSD, HC and CB as potential contributors to the development of inferior pneumatization of maxillary sinus.Alterations in sinus air pressure due to these obstructions might lead to pneumatization [8].

The purpose of this study is to determine the presence of $\mathrm{CB}, \mathrm{NSD}$ and $\mathrm{HC}$ on occurrence of maxillary sinus inferior pneumatization (MSIP) measured on CBCT scan. CBCT scan is an essential investigation to delineate the intricate anatomy of the sinuses of each individual patient [9]. In the current literature, the effect of these anatomic variations on MSIP is not reported.

\section{MATERIAL AND METHODS}

The subjects for this retrospective study consisted of all 300 patients who visited the Marmara University Faculty of Dentistry, and underwent a single CBCT examination picked up from the picture archiving and communications system (PACS) from 2011 to 2014. 
The CBCT examinations were performed using a ProMax 3D Mid machine (Planmeca Oy, Helsinki, Finland). The ProMax 3D Mid CBCT machine was operated at 90 $\mathrm{kVp}$ and $10 \mathrm{~mA}$ with a $9 \times 16 \mathrm{~cm}$ field of view. Assessment of CBCT scans was performed directly on a 1920x1080 pixel and 23-inch Acer monitor screen (Acer Inc., Taipei, Taiwan). Voxel edge length was $0.2 \mathrm{~mm}$ and slice thickness was $1 \mathrm{~mm}$. Patients with a history of trauma and/or surgery involving the maxillofacial region, systemic diseases affecting growth and development, or clinical and/or radiographic evidence of developmental anomalies/ pathologies affecting the maxillofacial region were excluded from the study. The study protocol was approved by the Local Committee of Research and Ethics of Medipol University with the number of 10640098-58.

One oral and maxillofacial surgeon $(\mathrm{GG})$ and one oral and maxillofacial radiologist (MOB) independently interpreted all of the images. A second oral and maxillofacial radiologist reviewed any contradictory findings. Scans were reviewed for any nasal cavity and/or paranasal anatomical abnormalities, with specific evaluation on the presence of $\mathrm{CB}$, NSD and HC. For defining them coronal images were selected. They were cropped in the slice in which their widest size was apparent. CB was defined as the presence of pneumatization of any size in the left or right within in the superior, middle, or inferior conchae. NSD was defined as a deviation of greater than $4 \mathrm{~mm}$ from the midline to the left or right. We used criteria for defining $\mathrm{HC}$ as air cells, of any size, located along the medial portion of the orbital floor and/or the lamina papyracea inferior to the bulla ethmoidalis, and continuous with the ethmoid capsule.
It is determined as pneumatized for dentate patients when the apices are surrounded by the sinus mucosa and for edentulous patients if the alveolar bone is less than $10 \mathrm{~mm}$ in vertical height.

Results were statistically analyzed using SPSS software (version 12; SPSS Inc, Chicago, Illinois). $P$ values $<0.05$ were considered statistically significant. Data was analyzed with a Chi-square test.

\section{RESULTS}

Of the 300 scans evaluated, 150 were from male patients and 150 were female patients: mean age $32.46 \pm 11.89$ years age ; range $20-70$ years. $44,3 \%$ of the patient scans reviewed had evidence of CB (Fig. 1). From the 300 scans, $12.7 \%$ were located in one of the right concha, $9 \%$ involving the left concha, and $22.6 \%$ bilaterally distributed. There was no statistical difference between gender and the presence of $\mathrm{CB}$. $48.7 \%$ female; $40 \%$ were male; $P=.352$ ) (Table 1) There was no statistical significance when comparing the relationship of patients with CB $(44.3 \%)$ and those with pneumatization $(27.7 \%) .14 .7 \%$ of patients had a combination of both, $29.7 \%$ had CB without evidence of pneumatization, and $13 \%$ had pneumatization in the absence of CB. (Table 2) The relationship between $\mathrm{CB}$ and ipsilateral or contralateral pneumatization was not statistically significant. $(P<.005)$ (Table 5$)$ $37.3 \%$ of the patient scans reviewed had evidence of NSD (Fig. 2). From the 300 scans, 23\% showed right side deviation, $14.3 \%$ presented left side deviation. There was a statistically significant higher prevalence of NSD in males $(54.7 \%)$ compared to females $(20 \% ; \mathrm{P}<.005)$ (Table 1$)$
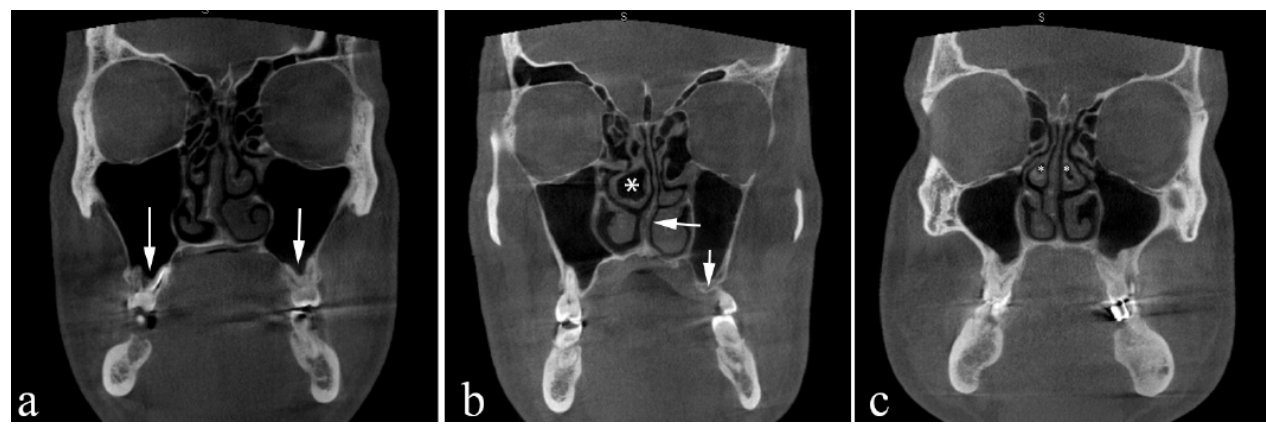

Fig. (1). Coronal CBCT scan demonstrating bilateral maxillary pneumatization (arrows). (a) Right middle concha bullosa (asterisk). Left nasal septal deviation (arrow). Left maxillary pneumatization (arrow) (b) Bilateral middle concha bullosa (asterisk).

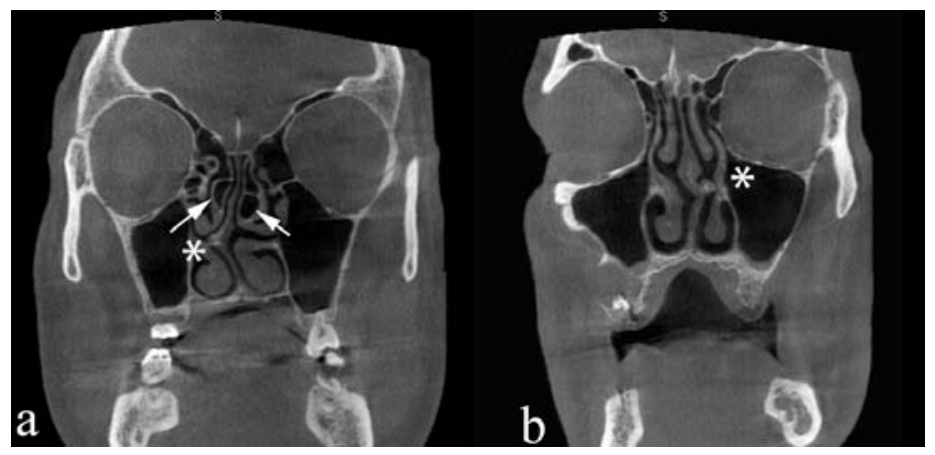

Fig. (2). Coronal CBCT scans demonstrating bilateral middle concha bullosa (arrows). (b) Right nasal septal deviation (asterisk) (a) Left nasal septal deviation (asterisk). No concha bullosa or Haller's cells is evident. 
Table 1. Prevalence and gender distribution of concha bullosa, nasal septal deviation, Haller's cells and maxillary pneumatization.

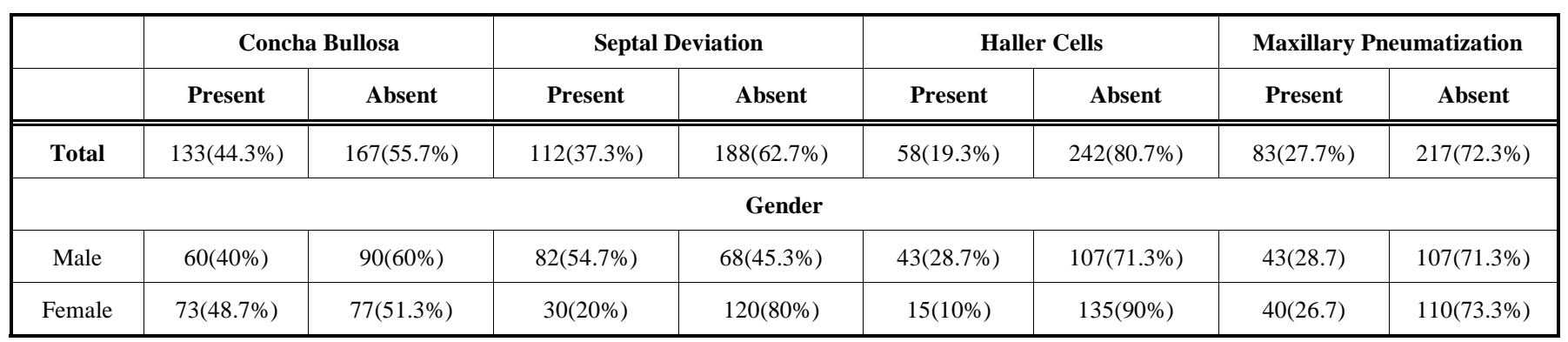

Table 2. Relationship of concha bullosa and pneumatization.

\begin{tabular}{|c|c|c|c|}
\hline & & \multicolumn{2}{|c|}{ Concha Bullosa } \\
\hline & & Present & Absent \\
\hline \multirow{2}{*}{ Pneumatization } & Present & $44(14.7 \%)$ & $39(13 \%)$ \\
\hline & Absent & $89(29.7 \%)$ & $128(42.7 \%)$ \\
\hline
\end{tabular}

Table 3. Relationship of nasal septal deviation and pneumatization.

\begin{tabular}{|c|c|c|c|}
\hline & & \multicolumn{2}{|c|}{ Nasal Septal Deviation } \\
\hline & & Present & Absent \\
\hline \multirow{2}{*}{ Pneumatization } & Present & $48(16 \%)$ & $35(11.7 \%)$ \\
\hline & Absent & $140(46.7 \%)$ & $77(25.7 \%)$ \\
\hline
\end{tabular}
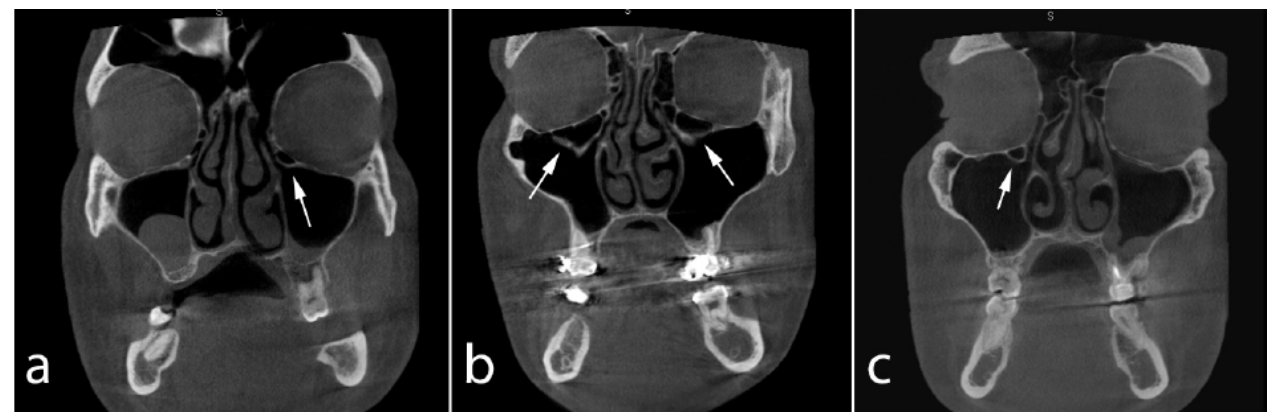

Fig. (3). Coronal CBCT images showing bilateral (b) and unilateral (a, c) Haller's cells (arrows).

There was no statistical significance when comparing the relationship of patients NSD $(37.3 \%)$ and those with pneumatization $(27.7 \%)$. $16 \%$ of patients had a combination of both, $46.7 \%$ had NSD without evidence of pneumatization, and $11.7 \%$ had pneumatization in the absence of NSD. $(P<$ .005) (Table 3) The relationship between septal deviation and ipsilateral or contralateral pneumatization was not statistically significant. $(P<.005)$ (Table 5) $19.3 \%$ of the patient scans reviewed had evidence of HC (Fig. 3). From the 300 scans, $2.7 \%$ were showed $\mathrm{HC}$ on the right, $9.3 \%$ presented on the left and $7.3 \%$ showed bilaterally. There was a statistically significant higher prevalence of HC in males $(28.7 \%)$ compared to females $(10 \% ; P<.005)$ (Table 1) There was no statistical significance when comparing the relationship of $\mathrm{HC}(19.3 \%)$ and those with pneumatization $(27.7 \%) .4 .7 \%$ of patients had a combination of both, $14.7 \%$ had HC with- out evidence of pneumatization, and $23 \%$ had pneumatization in the absence of HC. $(P<.005)$ (Table 4) The relationship between HC and ipsilateral or contralateral pneumatization was not statistically significant. $(P<.005)$ (Table 5)

\section{DISCUSSION}

The relations between the dental roots apices, alveolar bone and the sinus floor are critical for the diagnosis and management during teeth removal or placement of dental implants. Pneumatization of the sinus can lead to various complications, during these procedures. It is known that anatomical variations adjacent to maxillary sinus come along with changes in its morphology. Pneumatization is known to be affected from several factors, however it is unclear that if there is correlation with these variations. The aim of this 
Table 4. Relationship of Haller's cell and pneumatization.

\begin{tabular}{|c|c|c|c|}
\hline & & \multicolumn{2}{|c|}{ Haller's Cell } \\
\hline \multirow{3}{*}{ Pneumatization } & Present & Present & Absent \\
\cline { 2 - 4 } & Absent & $14(4.7 \%)$ & $69(23 \%)$ \\
\cline { 2 - 4 } & $44(14.7 \%)$ & $173(57.7 \%)$ \\
\hline
\end{tabular}

Table 5. Relationship of Haller's cell, septal deviation and concha bullosa with ipsilateral and contralateral pneumatization.

\begin{tabular}{|c|c|c|c|}
\hline \multirow{3}{*}{ Concha Bullosa } & & Ipsilateral Pneumatization Present & Contralateral Pneumatization Present \\
\cline { 2 - 4 } & Right & $4 / 16(25 \%)$ & $0 / 15(0 \%)$ \\
\cline { 2 - 4 } & Left & $1 / 15(6.6 \%)$ & $2 / 16(12.5 \%)$ \\
\hline \multirow{3}{*}{ Septal Deviation } & Bilateral & $14 / 52(26.9 \%)$ & $6 / 15(40 \%)$ \\
\cline { 2 - 4 } & Right & $4 / 16(25 \%)$ & $3 / 16(18.7 \%)$ \\
\hline \multirow{3}{*}{ Haller's Cell } & Right & $2 / 15(13.3 \%)$ & $0 / 15(0 \%)$ \\
\cline { 2 - 4 } & Left & $0 / 16(0 \%)$ & $2 / 16(12.5 \%)$ \\
\cline { 2 - 4 } & Bilateral & $1 / 15(6.6 \%)$ & \\
\hline
\end{tabular}

study was to answer the question: "Is there any relationship between these anatomic variations and inferior pneumatization of maxillary sinus and so they predispose to future pneumatization?" We hypothesized that CB, HC and NSD might effect pneumatization in the same way that they affect sinus pathology and morphology.

The clinical significance of HC gains importance considering its possible predisposing for chronic sinusitis [10]. They might be seen in isolation or in association with NSD and CB. Depending on the size and location of these anatomical variations, they may narrow the infundibular area and maxillary sinus ostium that these areas are easily occluded by even minor inflammation of the mucosa [11]. CB and NSD's relation with alterations in maxillary sinus morphology is well studied in current literature. Extreme hypertrophy of the inferior turbinates has been seen to remodel the medial wall in the inferior meatus into the sinus. Smith KD, et al. reviewed 883 CT scans for prevalence of $\mathrm{CB}$ and NSD and their potential relationships to maxillary sinusitis. They reported there was no statistically significant relationship between the presence of $\mathrm{CB}$ or NSD and maxillary sinusitis [12]. Collet $\mathrm{S}$, et al. reported a literature review that cannot establish a definite role to the nasal septum neither as the pathogenesis of chronic sinusitis nor as a contributing factor [13]. In our study, we selected these three anatomic variations because they commonly studied for their influence on alteration in maxillary sinus $[6,8]$. Caughey RJ, et al. reviewed 250 consecutive studies (500 sides), similar to our study, for NSD, CB and HC andtheir association with maxillary sinus disease. They reported that anatomical variations, which contribute to the narrowing of the osteomeatal complex, are associated with sinus disease. However, in our study, there was no statistically significant relationship between them and pneumatization.
Frequently encountered variations in antral volume and configuration involve posterior extension toward the zygoma (zygomatic recess), and inferior pneumatization into the dental alveolus about the roots of the posterior teeth, or between them in edentulous areas. Histologic examinations had shown that the pneumatization process occurs by osteoclastic resorption of the cortical walls of the sinus and the layering of osteoid inferior to it [14]. Physiological appositional growth of bone may eventuate pneumatization and tooth extraction accelerates this process. However, hereditary factors, density of the bone, factors fluctuating sinus air pressure might have efficiency on pneumatization. Consequently, sinus pneumatization process is under unclear and multifactorial mechanism. In our study we aimed to clarify in particular, the potency of these three anatomic variations on sinus pneumatization. Pneumatization might be affected from narrowing of osteomeatal complex and accompanying maxillary sinus disease. However, we could not find any statistically significant relationship between ipsilateral or contralateral pneumatization with these anatomical variations.

In conclusion, we could not establish a definite role of septal deviation, concha bullosa and Haller's cell on sinus pneumatization. They do not indicate a direct influence on sinus pneumatization like they might do in sinus pathology. Their absence or presence does not offer a statistically significant change with sinus pneumatization. The outcomes of this study did not clarify the query, that should we consider inferior pneumatization in a case of encountering these anatomical variations and support the hypothesis of potential correlation. Sinus pneumatization is affected from various physiological, anatomical and environmental factors. Further studies are necessary to understand associated factors and the mechanism of this process. 


\section{CONFLICT OF INTEREST}

The authors confirm that this article content has no conflict of interest.

\section{ACKNOWLEDGEMENTS}

Declared none.

\section{REFERENCES}

[1] Thomas A, Raman R. A comparative study of the pneumatization of the mastoid air cells and the frontal and maxillary sinuses. AJNR Am J Neuroradiol 1989; 10(Suppl 5): S88.

[2] Nowak R, Mehlis G. Studies on the state of pneumatization of the sinus maxillaris. Anat Anz 1975; 138(3): 143-51.

[3] Lawson W, Patel ZM, Lin FY. The development and pathologic processes that influence maxillary sinus pneumatization. Anat Rec (Hoboken) 2008; 291(11): 1554-63.

[4] Shapiro R, Schorr S. A consideration of the systemic factors that influence frontal sinus pneumatization. Invest Radiol 1980; 15(3): 191-202.

[5] Sharan A, Madjar D. Maxillary sinus pneumatization following extractions: a radiographic study. Int J Oral Maxillofac Impl 2008; 23(1): 48-56.

[6] Stallman JS, Lobo JN, Som PM. The incidence of concha bullosa and its relationship to nasal septal deviation and paranasal sinus disease. Am J Neuroradiol 2004; 25(9): 1613-8.
Kim SK, Heo GE, Seo A, Na Y, Chung SK. Correlation between nasal airflow characteristics and clinical relevance of nasal septal deviation to nasal airway obstruction. Resp Physiol Neurobiol 2014; 192: 95-101.

[8] Kantarci M, Karasen RM, Alper F, Onbas O, Okur A, Karaman A. Remarkable anatomic variations in paranasal sinus region and their clinical importance. Eur J Radiol 2004; 50(3): 296-302.

[9] Berenholz L, Kessler A, Lapinsky J, Segal S, Shlamkovitch N. Nasal obstruction in the adult: is CT scan of the sinuses necessary? Rhinology 2000; 38(4): 181-4.

[10] Wanamaker HH. Role of Haller's cell in headache and sinus disease: a case report. Otolaryngol Head Neck Surg 1996; 114(2): 324-7.

[11] Liu X, Zhang G, Xu G. Anatomic variations of the ostiomeatal complex and their correlation with chronic sinusitis: CT evaluation. Zhonghua Er Bi Yan Hou Ke Za Zhi 1999; 34(3): 143-6.

[12] Smith KD, Edwards PC, Saini TS, Norton NS. The prevalence of concha bullosa and nasal septal deviation and their relationship to maxillary sinusitis by volumetric tomography. Int J Dent 2010; 2010: 1-5.

[13] Collet S, Bertrand B, Cornu S, Eloy P, Rombaux P. Is septal deviation a risk factor for chronic sinusitis? Review of literature. Acta Otorhinolaryngol Belg 2001; 55(4): 299-304.

[14] Wehrbein H, Diedrich P. The initial morphological state in the basally pneumatized maxillary sinus--a radiological-histological study in man. Fortschr Kieferorthop 1992; 53(5): 254-62.

Received: October 10,2014

Revised: November 17, 2014

Accepted: May 25, 2015

(C) Göçmen et al.; Licensee Bentham Open.

This is an open access article licensed under the terms of the Creative Commons Attribution Non-Commercial License (http://creativecommons.org/licenses/by-nc/3.0/) which permits unrestricted, non-commercial use, distribution and reproduction in any medium, provided the work is properly cited. 